\title{
Intrathecal complement activation by the classical pathway in tick-borne encephalitis
}

\author{
Malin Veje $^{1}$ (D) $\cdot$ Marie Studahl $^{1} \cdot$ Tomas Bergström $^{1}$
}

Received: 31 October 2018 / Revised: 4 February 2019 / Accepted: 14 February 2019 / Published online: 8 March 2019

(C) The Author(s) 2019

\begin{abstract}
Tick-borne encephalitis (TBE) is one of the most prevalent viral central nervous system (CNS) infections in Eurasia and neurological sequelae are common. The immune responses are considered crucial for the pathogenesis. The aim of this study was to explore the activation of the complement system in TBE. The complement system is a part of the innate immune response in the CNS, which previously has been reported to be activated in other flavivirus infections. We analyzed complement factors in 44 paired cerebrospinal fluid (CSF) and serum samples from 20 cases of TBE in the acute and later stages, as well as in serum and CSF from 32 healthy controls. The concentrations of complement factors C1q, C3a, C3b, and C5a were determined with commercially available ELISA kits. Clinical data to categorize the severity of disease and outcome was retrieved from the medical records of the TBE patients. We found significantly higher concentrations of all of the analyzed complement factors in the CSF from TBE patients compared to the healthy controls. In particular, the marked increment of C1q concentrations in the CSF ( $p<0,001$ as compared to controls) indicated an intrathecal activation by the classical pathway. There was no correlation between complement factor concentrations in the CSF and severity of the disease in the acute phase or with sequelae at 6 months follow-up. We have found an intrathecal complement activation in TBE, and the marked increase of complement factor C1q indicated an activation by the classical pathway.
\end{abstract}

Keywords Tick-borne encephalitis (TBE) $\cdot$ Complement $\cdot \mathrm{C} 1 \mathrm{q} \cdot$ Intrathecal activation

\section{Introduction}

Tick-borne encephalitis (TBE) is one of the most prevalent viral central nervous system (CNS) infections in Eurasia and neurological sequelae are common in adults as well as in children. The TBE virus (TBEV) belongs to the genus Flavivirus, other important human pathogenic viruses in this group being dengue, yellow fever, Zika, Japanese encephalitis, and West Nile viruses. TBEV is spread by ticks, with rodents as intermediate hosts (Lindquist and Vapalahti 2008). Findings of TBEV RNA in cerebrospinal fluid (CSF) are rare (Saksida et al. 2005; Veje et al. 2018), but viral RNA has been detected

Malin Veje

malin.veje@vgregion.se

1 Department of Infectious Diseases, Institute of Biomedicine, Sahlgrenska Academy, University of Gothenburg,

Gothenburg, Sweden in the brain in fatal cases (Kuivanen et al. 2015; Tomazic et al. 1997). Although the host immune response to the virus is considered to be a major contributor to the CNS tissue destruction in TBE, such reactions have not been fully characterized (Růžek et al. 2009).

The complement system constitutes a part of the innate immune system, and is mainly activated by three routes: the Classical, the Lectin, and the Alternative pathways (Fig. 1). As a reaction to pathogens and trauma, several different proteins are produced and take part in a cascade of activation steps, leading to a direct immunological response as well as activation of the adaptive immune system (Shastri et al. 2013). Complement activation in the CNS has been most extensively studied in the host defense against bacterial and fungal infections (Shen et al. 2017; Mook-Kanamori et al. 2014; Henningsson et al. 2007). In viral infections, we have reported that $\mathrm{C} 3 \mathrm{a}, \mathrm{C} 3 \mathrm{~b}, \mathrm{C} 5$, and $\mathrm{C} 5 \mathrm{a}$ increased intrathecally in the acute stage in patients with herpes simplex encephalitis (HSE) and that $\mathrm{C} 3 \mathrm{a}$ and $\mathrm{C} 5 \mathrm{a}$ remained increased in later stages, suggesting that complement activation may also be a part of a chronic neuroinflammation (Eriksson et al. 2016). There has been an 
Fig. 1 Overview of the three major complement system activation pathways and the terminal pathway. Reproduced with permission from Charlotta Eriksson (Thesis, Gothenburg University, 2016)

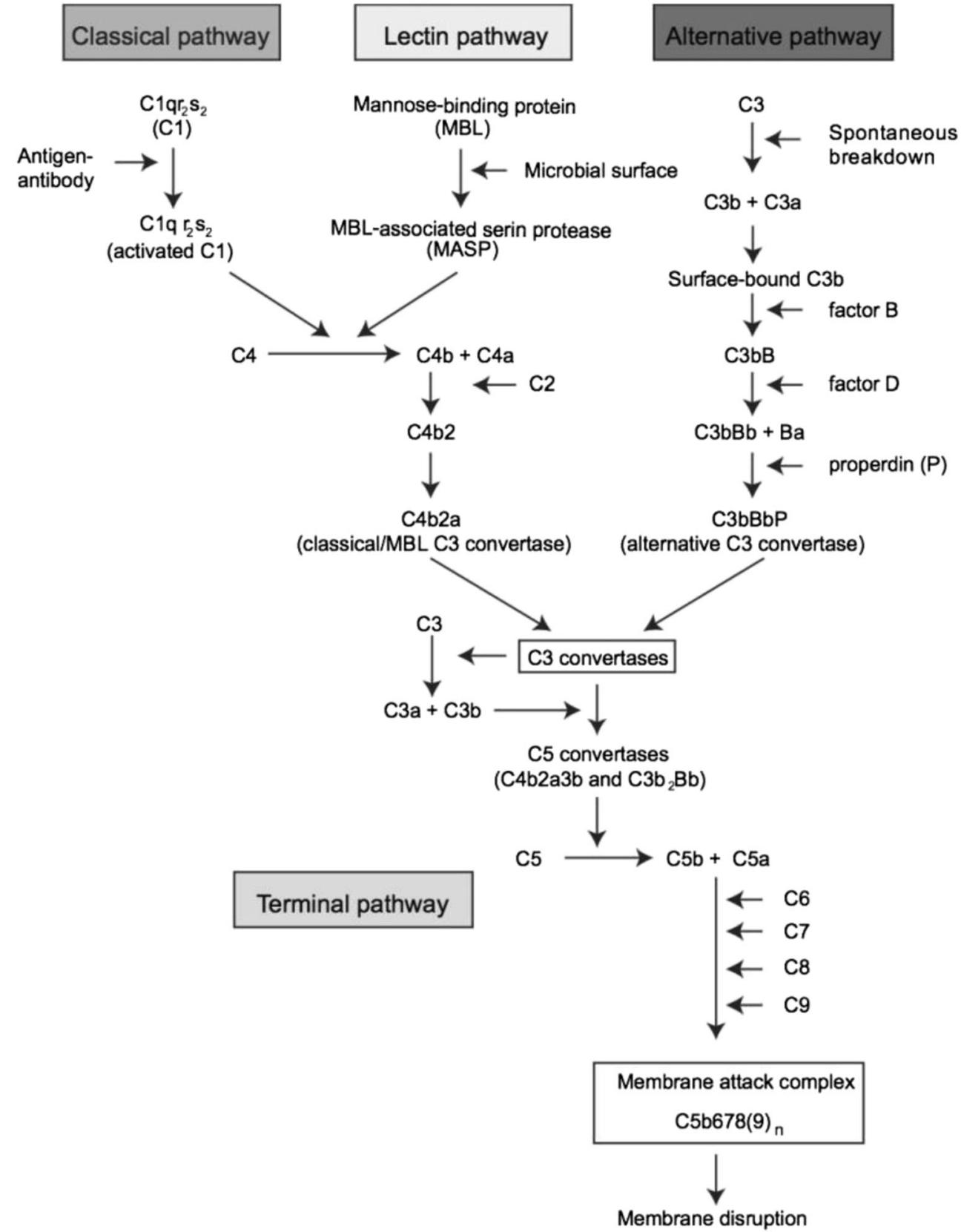

interest in the role of complement activation in another flavivirus infection of the CNS, West Nile virus (Mehlhop et al. 2007; Mehlhop and Diamond 2006; Mehlhop et al. 2009a; Mehlhop et al. 2009b; Mehlhop et al. 2005). In cell cultures and in mice models, complement activation is required for antibody-mediated neutralization, and especially $\mathrm{C} 1 \mathrm{q}$ seems to have a crucial role for this function (Mehlhop et al. 2007; Mehlhop et al. 2009b).

The role of complement activation for the pathogenesis of TBE has not been established. To this end, the aim of our study was to determine concentrations of the complement activation factors C1q, C3a, C3b, and C5a, in serum and CSF in samples from TBE patients and compare those to samples from healthy controls. Here, we found a strong intrathecal complement activation as part of the innate immune response against TBEV.

\section{Materials and methods}

\section{TBE patients}

Serum and cerebrospinal fluid (CSF) samples were drawn from prospectively included patients with TBE at the Department of Infectious Diseases, Sahlgrenska University Hospital, during the period 2014-2017. All 
TBE patients above 18 years of age, admitted to the inpatient clinic or referred to the outpatient clinic, were asked to join the study. There were no exclusion criteria except inability to give oral and written consent (patient and/or next of kin). All cases had positive TBEVspecific IgM and IgG antibodies in serum (Enzygnost Anti-TBE Virus (IgG, IgM), Siemens) and were confirmed according to the ECDC definition (ECDC Meeting Report 2011 2012) from 2011, where a confirmed TBE case requires both clinical symptoms of TBE and IgM plus IgG in serum or IgM in the CSF or IgM plus IgG in the CSF or detection of TBE viral nucleic acid in clinical specimen. Patient samples with both serum and CSF from the same date were included in the study.

The medical records were studied and a clinical classification of the severity of the symptoms in the acute phase, i.e. "mild," "moderate," or "severe," was performed, according to our previous study (Veje et al. 2016). Mild disease was defined as primarily meningeal symptoms like fever, headache, nausea, vomiting, neck stiffness, and sensitivity to light and sound with a normal EEG or EEG not performed. Moderate disease was defined as moderate signs of encephalitis without or with slightly altered consciousness, and/or diffuse neurological symptoms such as confusion, slow thinking, or focal neurological symptoms such as ataxia, tremor, or dysphasia. Severe disease was defined as multifocal symptoms and/or severe signs of encephalitis with altered consciousness.

The medical records at the clinical follow-ups were analyzed, and the patients were divided into two groups, "fully recovered" and "sequelae," based on data from clinical examinations after approximately 3, 6, and 12 months.

\section{Healthy controls}

Frozen paired CSF and serum biobank samples, drawn from 32 healthy control persons in a previous study (Persson et al. 2014), were thawed at room temperature and analyzed for complement factors. These subjects were recruited by advertisement at the Center of Blood Donation at the Sahlgrenska University Hospital.

\section{Determination of complement factors}

The concentrations of the complement factors C1q, C3a, C3b, and C5a were analyzed in serum and CSF with commercially available ELISA kits, according to the instructions supplied by the manufacturers (Cusabio Biotech for $\mathrm{C} 3 \mathrm{~b}$ and CloudClone Corp. for the others). The respective kit sensitivity and specificity was provided by the producers, as previously described (Eriksson et al. 2016).

\section{Statistical analysis}

GraphPad Prism version 7.0 (GraphPad Software, La Jolla California, USA) was used for statistical analyses and graph constructions. Comparisons were made by the Mann-Whitney $U$ test, where a $p$ value $<0.05$ was considered significant.

\section{Results}

\section{Patients and controls}

The control group was younger than the TBE patient group and consisted of a higher proportion of men. There was a wider age range in the TBE group (3488 years) compared to the control group (18-57 years) (Table 1). According to the definition above, four patients (20\%) had a mild TBE disease, 15 patients $(75 \%)$ a moderate, and one patient ( $5 \%)$ suffered from a severe disease. For each patient, one $(n=5)$, two $(n=6)$ or three $(n=9)$ paired CSF/serum samples were available. All in all, 44 paired samples were analyzed for complement factors, drawn with a range from 0 to 327 days after fever onset, four samples on days $0-7,24$ samples on days 8-31, nine samples on days 32-90, and seven samples were drawn on days 91-327 after fever onset. 42/44 of the paired serum CSF samples were drawn on the same day, while 2/44 within 1 day apart. During the study period, 19 TBE patients were admitted to the inpatient clinic. Of these, 16 were included in the study and three of the study patients were included after referral from other departments (e.g., internal medicine, neurology) to our outpatient clinic. One of the patients was hospitalized with TBE in 2012 but was not referred to the outpatient clinic until 2016, when he was included in the study.

\section{Complement activation in TBE patients}

Compared to the controls, the TBE patients had significantly higher levels of all of the analyzed complement factors in the CSF (Fig. 2). C1q, a complement factor part of the classical pathway, was detected in higher concentrations than $\mathrm{C} 3 \mathrm{a}, \mathrm{C} 3 \mathrm{~b}$, and $\mathrm{C} 5 \mathrm{a}$. Regarding the serum samples, the complement factor concentrations were generally higher in the patient than in the control group, but there was no statistical difference between the patient and the control group, except for the C5a concentrations, which were statistically higher in the controls than in the sera from the TBE group. 
Table 1 Characteristics of the included tick-borne encephalitis (TBE) patients and controls

\begin{tabular}{lll}
\hline & $\begin{array}{l}\text { TBE patients } \\
(n=20)\end{array}$ & $\begin{array}{l}\text { Control persons } \\
(n=32)\end{array}$ \\
\hline Median age, years (range) & $52.5(34-88)$ & $30(18-57)$ \\
Male gender & $11(55 \%)$ & $20(62.5 \%)$ \\
Concomitant diseases* & $9 / 20(45 \%)$ & - \\
Number of CSF samples & 44 & 32 \\
Number of serum samples & 44 & 32 \\
\hline
\end{tabular}

* $11 / 20$ patients were previously completely healthy. Of the 9 patients with concomitant diseases, 2/9 had substitution treatment for hypothyroid, 2/9 were treated for hypertonia, 2/9 had treatment for depression and/or bipolar disease, 6/9 had musculoskeletal pain, 1/9 was operated for mammalian cancer, 1/9 was operated for colon cancer, $1 / 9$ was treated with estrogen substitution, and 1/9 had chronic obstructive lung disease. Neither of the patients were on immunosuppressive treatment

\section{Complement activation in relation to disease severity and age}

Since the vast majority of the patients (15/20) suffered from a moderate disease, correlation between disease severity and complement factor concentrations could not be properly investigated. One patient had markedly higher $\mathrm{C} 3 \mathrm{~b}$ concentrations in the CSF compared to the other patients. This was a $65-$ year-old male, suffering from a paresis in his right arm and hand, without improvement at the 12-months' -follow-up, despite intense rehabilitation. The $\mathrm{C} 5 \mathrm{a}$ concentration in the CSF was markedly higher in one 40-year-old female, compared to the other patients. She was 30 weeks pregnant with twins and suffered from severe encephalitis, with incomplete recovery after 12 months.

We found no correlation between the patients' age and complement factor concentrations in the first CSF sample (drawn on days 7-79 (median 19.5) after fever onset) or between complement activation and intrathecal mononuclear pleocytosis in the first CSF sample (data not shown).

\section{Kinetics of complement activity in acute and later stages of TBE}

The kinetics of the different complement factors, shown for paired samples of CSF and serum for the time periods of $0-7$, 8-31, 32-90, and 91-327 days after fever onset, are found in Fig. 3. In serum, the concentrations of complement factors were rather stable over time and the concentrations were generally around tenfold higher in serum than in the CSF. Intrathecally, the complement concentrations diminished rapidly within the first 3 months after the infection, this pattern being most pronounced in the $\mathrm{Clq}$ concentrations, which were higher than the concentrations of $\mathrm{C} 3 \mathrm{a}, \mathrm{C} 3 \mathrm{~b}$, and C5a. More than 3 months after disease onset, there was still detectable intrathecal complement activation of the complement factors $\mathrm{C} 1 \mathrm{q}$ and $\mathrm{C} 3 \mathrm{~b}$ (Fig. 3a, e).

\section{Complement activation in relation to sequelae}

Medical records regarding symptoms at minimum 3 months follow-up (range 3-6 months) were available in $14 / 20$ patients. One patient was lost to follow-up, three patients had withdrawn from the study, one patient was temporarily lost to follow-up and had his first revisit 10 months after the infection, and one patient had no follow-up visit at 6 months because he was included 4 years after the infection and saved samples from the acute phase were analyzed. In 14/20 patients, we had follow-up data in minimum 6 months after disease onset (range 6.5-11 months), and follow-up data 12 months after the infection (range 12-17 months) was available in 10/20 patients. At 3 months, $12 / 14(85.7 \%)$ of the patients still experienced symptoms, at 6 months $10 / 14$ (71.4\%), and 1 year after the onset of disease $9 / 10$ patients $(90 \%)$ still suffered from sequelae.

We compared the intrathecal complement factor concentrations between the fully recovered patients with the patients suffering from sequelae at the different follow-up time points (3, 6, and 12 months), and found no statistical difference between the groups, except for at the 3 months follow-up, where the fully recovered patients had significantly higher levels of the complement factor $\mathrm{C} 3 \mathrm{~b}$ compared to the patients with sequelae (data not shown).

\section{Discussion}

Given the limited data available on intrathecal complement activation in viral CNS infections in general, and in TBE in particular, our study may increase understanding of the innate CNS immune response to this virus. Our samples were drawn at different stages of the disease, which gave us the opportunity to study complement activation at various time points during the disease course. It was evident that the intrathecal activation of the complement system was strong and rapid in patients with TBE, and that, based on high levels of complement factor Clq in the CSF, the classical pathway was utilized. 
Fig. 2 Box and whiskers plot displaying a comparison of complement factor C1q, C3a, $\mathrm{C} 3 \mathrm{~b}$, and $\mathrm{C} 5 \mathrm{a}$ concentrations (ng/ $\mathrm{mL}$ ) in cerebrospinal fluid (CSF) and serum samples, measured with enzyme-linked immunosorbent assays (ELISAs), from TBE patients and controls. Lines showing medians and interquartile ranges, whiskers at minimum and maximum values

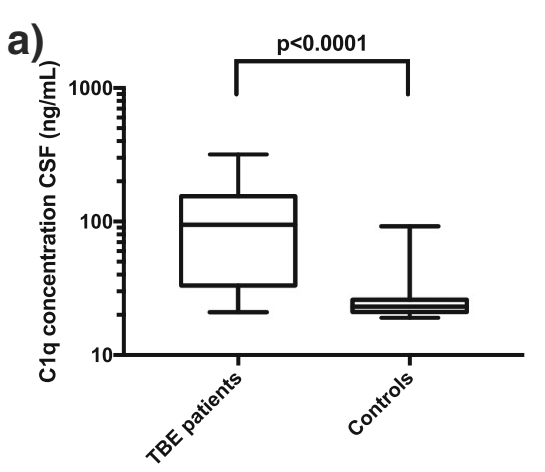

c)

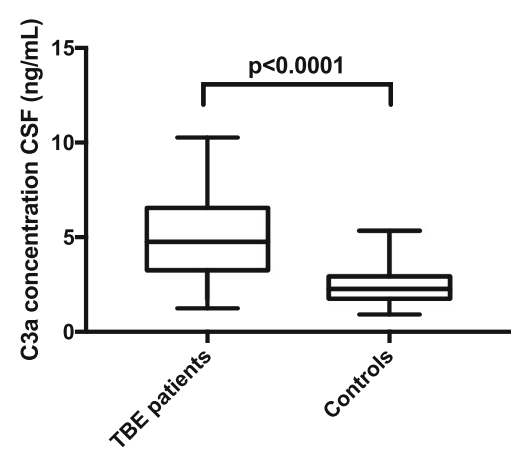

e)

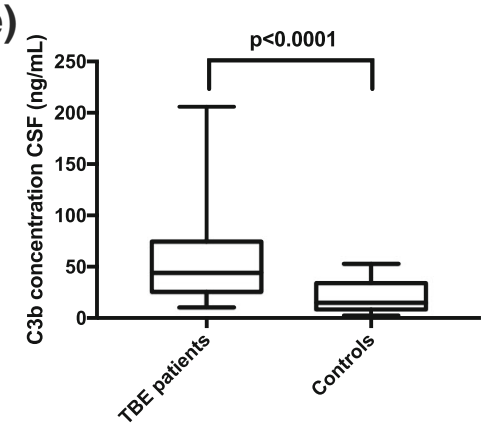

g)

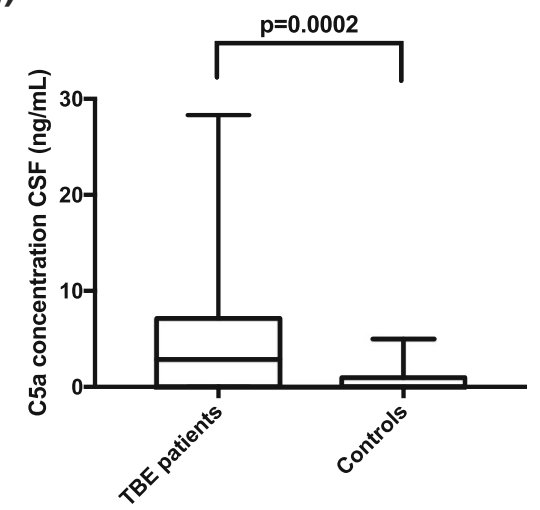

b)

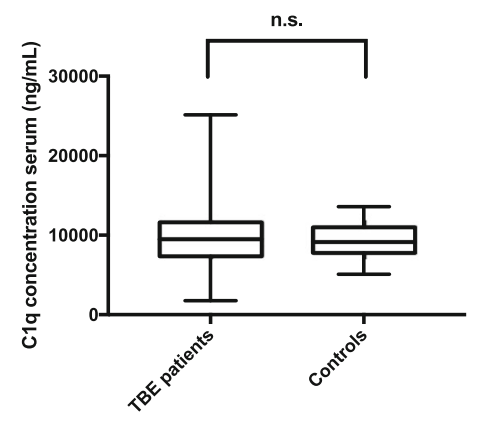

d)

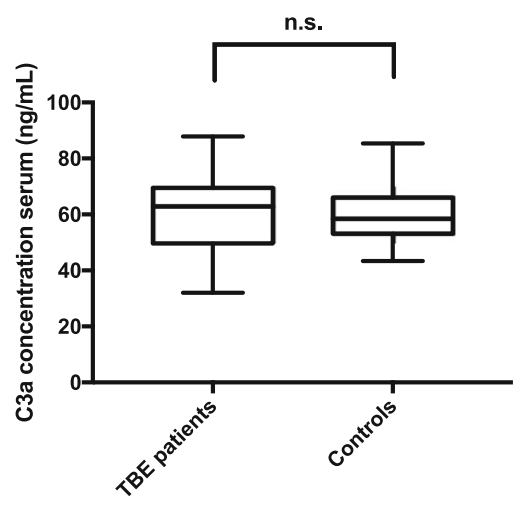

f)

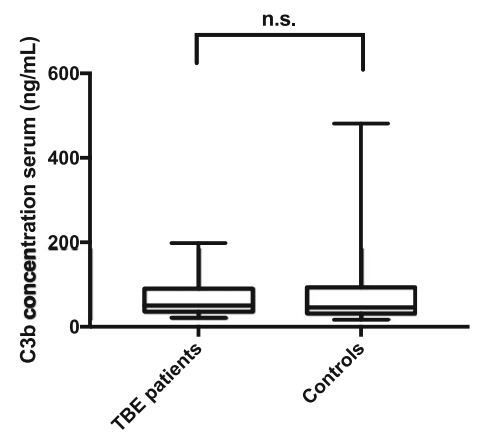

h)

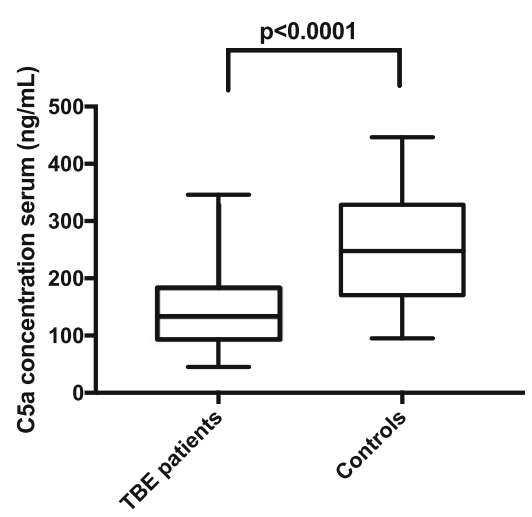

The immune response against TBEV involves several components. Serum levels of cytokines are elevated in TBE patients compared to controls (Palus et al. 2015). In mouse models, increased permeability of the blood- brain-barrier in TBEV infection is preceded by high levels of cytokines and chemokines in the brain (Ruzek et al. 2011). Neopterin and beta 2 microglobulin are produced by monocytes and macrophages in response to infection 
a)

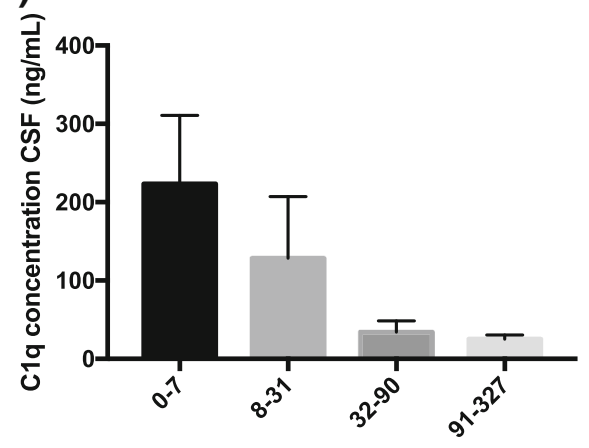

c)

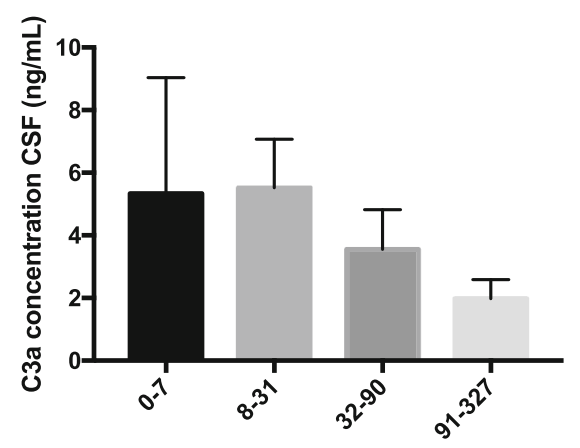

Days after fever onset

e)

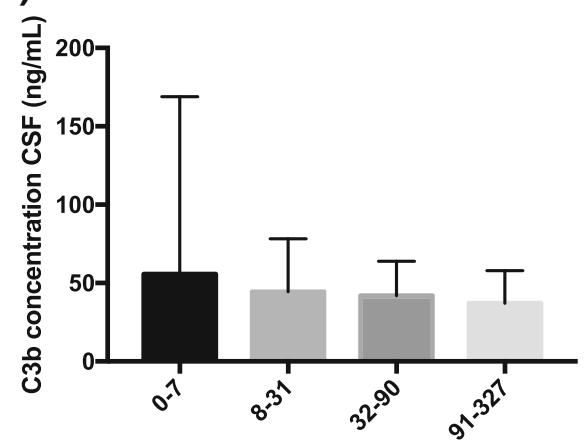

g)

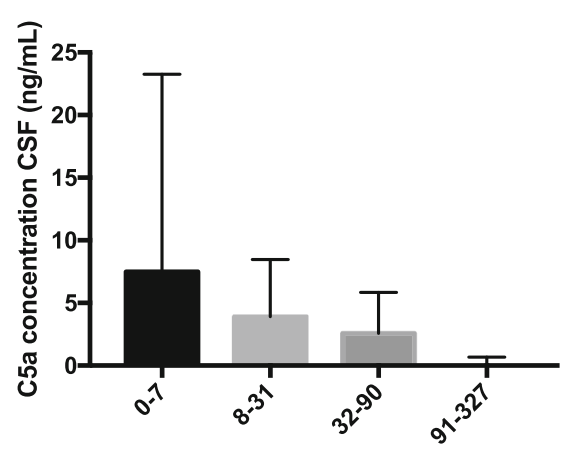

Days after fever onset

Fig. 3 Box and whiskers plot of distributions of cerebrospinal fluid (CSF) and serum concentrations $(\mathrm{ng} / \mathrm{mL})$ of complement factors $\mathrm{C} 1 \mathrm{q}, \mathrm{C} 3 \mathrm{a}, \mathrm{C} 3 \mathrm{~b}$, and $\mathrm{C} 5 \mathrm{a}$, measured with enzyme-linked immunosorbent assays (ELISAs), in TBE patients at different time points after the infection. b)

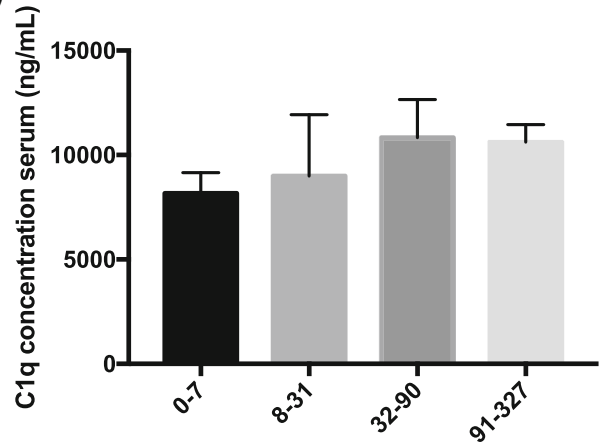

d)

Days after fever onset

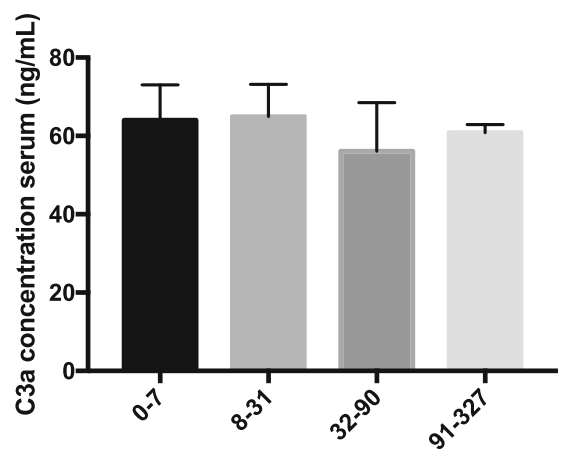

Days after fever onset

f)

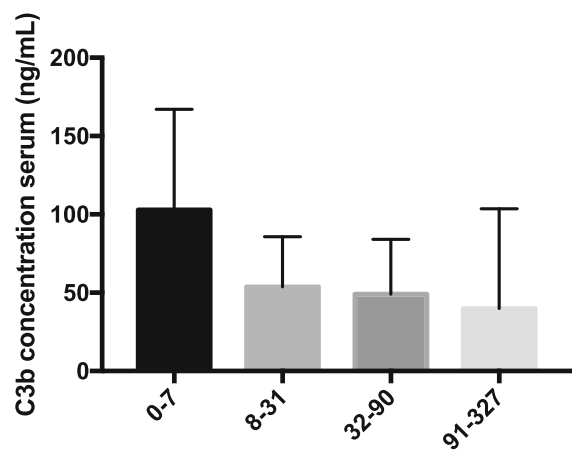

h)

Days after fever onset

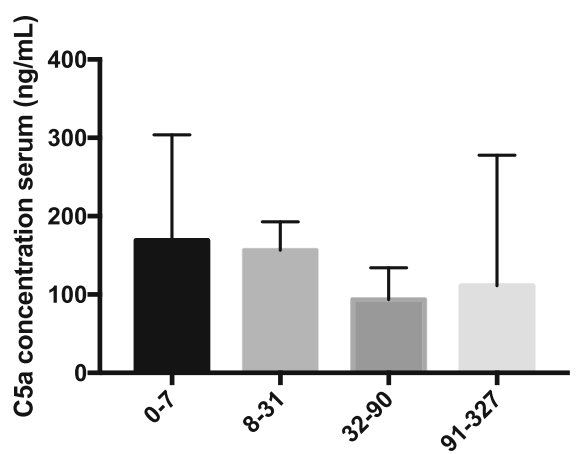

Days after fever onset

Days 0-7: number of samples, $n=4$, days 8-31: $n=24$, days 32-90: $n=9$, days 91-327: $n=7$. Median concentrations are presented for each time period, with interquartile ranges indicated with error bars 
and are proposed to be surrogate markers for $\mathrm{T}$ cell and lymphocyte activity (Gunther et al. 1996).

Although the understanding of intrathecal complement activation is incomplete, previous studies have found that several complement factors were upregulated in CNS infections and other brain diseases (Shen et al. 2017; Michailidou et al. 2015; Ager et al. 2010; Kasanmoentalib et al. 2017; Hellewell 2012). The clinical relevance of complement activation might have several facets. For example, $\mathrm{C} 3 \mathrm{a}$ added to the nasal mucosa of mice can decrease the neurological sequelae after ischemic stroke (Stokowska et al. 2017). C1q and the classical complement pathway have been found to be important in Alzheimer's disease as well as in normal aging (Stephan et al. 2013). C5a is a pro-inflammatoric substance and has been connected to several conditions, such as inflammatory disorders and sepsis (Guo and Ward 2005). Elevated levels of complement factors in plasma have been detected in pregnant women (Richani et al. 2005). The patients in our study were older than the healthy controls, which might have influenced the results. However, our study did not detect any correlation between age and complement factor concentration, presumably due to the small sample size.

Infection with West Nile virus (WNV), a mosquito-borne flavivirus with genetic similarity to TBEV, is known to elicit complement activation. This has been shown both in in vitro and in animal studies (Mehlhop et al. 2007; Mehlhop and Diamond 2006; Mehlhop et al. 2009a; Mehlhop et al. 2009b; Mehlhop et al. 2005). In a mouse model of WNV infection, complement factor $\mathrm{C} 1 \mathrm{q}$ appeared to boost the WNV antibody activity, and in the presence of C1q, the number of WNV antibodies needed to neutralize the virus was lowered (Mehlhop et al. 2009b). Dengue virus (DENV), another flavivirus, also activates the complement system (Conde et al. 2017). In the present study, significantly higher C1q concentrations were detected in TBE patients than in healthy controls. Furthermore, the here reported $\mathrm{C} 1 \mathrm{q}$ concentrations where higher than both the $\mathrm{C} 3 \mathrm{a}, \mathrm{C} 3 \mathrm{~b}$, and $\mathrm{C} 5 \mathrm{a}$ concentrations. The finding that complement factor $\mathrm{Clq}$ may play an important role in the immune response to TBEV is in line with data from previous studies on WNV and DENV (Mehlhop et al. 2007; Mehlhop and Diamond 2006; Mehlhop et al. 2009b; Conde et al. 2017). Interestingly, factor C5a concentrations were lower in peripheral blood in patients compared to controls, possibly explained by binding to leukocyte receptors as a control mechanism against systemic effects (Oppermann and Gotze 1994). The majority of TBE patients have leukocytosis in peripheral blood when neurological symptoms are present (Kaiser 1999) and leukocytosis is a prerequisite for removal of C5a from the blood (Oppermann and Gotze 1994).

No correlation was found between intrathecal complement factor concentrations and sequelae. Due to drop-out during follow-up in the study, we could only retrieve 12 months' data on $10 / 20$ patients, and only one of those patients was fully recovered. This might suggest a bias of drop-out from the study, where the recovered patients were less motivated to be followed up in the study. Perhaps this potential bias could also influence the difference in complement factor concentrations between patients and controls. However, both the patient who was fully recovered at 12 months, and a preponderance (6/9) of the patients with sequelae, had a moderate disease severity in the acute phase. The large proportion of patients with a moderate disease severity in our study $(75 \%)$, which is higher than in other TBE studies, (Mickiene et al. 2002; Kaiser 2012), could be at least partly explained by the fact that the study only included hospitalized patients.

The role, and especially the kinetics, of complement activation in TBE needs to be further elucidated. This innate immune response could serve both as a protection towards the viral infection and source of inflammation, which may contribute to the pathogenesis of this infection. In the future, detailed knowledge of the host immune response to TBEV will be essential to facilitate the choice of immunomodulary drugs to be tested together with antivirals.

Acknowledgements We thank Maria Johansson and Charlotta Eriksson for skillful analytic work.

Funding This work was supported by the Inter-Reg foundation to the project ScandTick Innovation and grants from the ALF foundation of Sahlgrenska Academy at the University of Gothenburg.

\section{Compliance with ethical standards}

The study was approved by the Gothenburg Ethical Committee (EPN 229-14) and informed written consent was obtained from all patients and controls (EPN 361-96).

Conflict of interest The authors declare that they have no conflicts of interest.

Open Access This article is distributed under the terms of the Creative Commons Attribution 4.0 International License (http:// creativecommons.org/licenses/by/4.0/), which permits unrestricted use, distribution, and reproduction in any medium, provided you give appropriate credit to the original author(s) and the source, provide a link to the Creative Commons license, and indicate if changes were made.

Publisher's note Springer Nature remains neutral with regard to jurisdictional claims in published maps and institutional affiliations.

\section{References}

Ager RR, Fonseca MI, Chu SH, Sanderson SD, Taylor SM, Woodruff TM, Tenner AJ (2010) Microglial C5aR (CD88) expression correlates with amyloid-beta deposition in murine models of Alzheimer's disease. J Neurochem 113:389-401

Conde JN, Silva EM, Barbosa AS, Mohana-Borges R (2017) The complement system in flavivirus infections. Front Microbiol 8:213 
ECDC Meeting Report 2011 (2012) Second expert consultation on tickborne diseases with emphasis on Lyme borreliosis and tick-borne encephalitis. https://ecdc.europa.eu/sites/portal/files/media/en/ publications/Publications/1102_MER_Tickborne_2010.pdf. Accessed 26.02.2019

Eriksson CE, Studahl M, Bergstrom T (2016) Acute and prolonged complement activation in the central nervous system during herpes simplex encephalitis. J Neuroimmunol 295-296:130-138

Gunther G, Haglund M, Lindquist L, Skoldenberg B, Forsgren M (1996) Intrathecal production of neopterin and beta 2 microglobulin in tickborne encephalitis (TBE) compared to meningoencephalitis of other etiology. Scand J Infect Dis 28:131-138

Guo RF, Ward PA (2005) Role of C5a in inflammatory responses. Annu Rev Immunol 23:821-852

Hellewell SCM-KMC (2012) Guilty molecules, guilty minds? The conflicting roles of the innate immune response to traumatic brain injury. Mediat Inflamm 2012:1-18

Henningsson AJ, Ernerudh J, Sandholm K, Carlsson SA, Granlund H, Jansson C, Nyman D, Forsberg P, Nilsson Ekdahl K (2007) Complement activation in Lyme neuroborreliosis-increased levels of $\mathrm{C} 1 \mathrm{q}$ and $\mathrm{C} 3 \mathrm{a}$ in cerebrospinal fluid indicate complement activation in the CNS. J Neuroimmunol 183:200-207

Kaiser R (1999) The clinical and epidemiological profile of tick-borne encephalitis in southern Germany 1994-98: a prospective study of 656 patients. Brain. 122(Pt 11):2067-2078

Kaiser R (2012) Tick-borne encephalitis: clinical findings and prognosis in adults. Wien Med Wochenschr 162:239-243

Kasanmoentalib ES, Valls Seron M, Ferwerda B, Tanck MW, Zwinderman AH, Baas F, van der Ende A, Brouwer MC, van de Beek D (2017) Mannose-binding lectin-associated serine protease 2 (MASP-2) contributes to poor disease outcome in humans and mice with pneumococcal meningitis. J Neuroinflammation 14:2

Kuivanen S, Smura T, Rantanen K, Kämppi L, Kantonen J, Kero M, Jääskeläinen A, Jääskeläinen AJ, Sane J, Myllykangas L, Paetau A, Vapalahti O (2018) Fatal tick-borne encephalitis virus infections caused by Siberian and European subtypes, Finland, 2015. Emerg Infect Dis 24:946-948

Lindquist L, Vapalahti O (2008) Tick-borne encephalitis. Lancet. 371: 1861-1871

Mehlhop E, Diamond MS (2006) Protective immune responses against West Nile virus are primed by distinct complement activation pathways. J Exp Med 203:1371-1381

Mehlhop E, Whitby K, Oliphant T, Marri A, Engle M, Diamond MS (2005) Complement activation is required for induction of a protective antibody response against West Nile virus infection. J Virol 79: 7466-7477

Mehlhop E, Ansarah-Sobrinho C, Johnson S, Engle M, Fremont DH, Pierson TC, Diamond MS (2007) Complement protein C1q inhibits antibody-dependent enhancement of flavivirus infection in an IgG subclass-specific manner. Cell Host Microbe 2:417-426

Mehlhop E, Fuchs A, Engle M, Diamond MS (2009a) Complement modulates pathogenesis and antibody-dependent neutralization of West Nile virus infection through a C5-independent mechanism. Virology. 393:11-15

Mehlhop E, Nelson S, Jost CA, Gorlatov S, Johnson S, Fremont DH, Diamond MS, Pierson TC (2009b) Complement protein C1q reduces the stoichiometric threshold for antibody-mediated neutralization of West Nile virus. Cell Host Microbe 6:381-391

Michailidou I, Willems JG, Kooi EJ et al (2015) Complement C1q-C3associated synaptic changes in multiple sclerosis hippocampus. Ann Neurol 77:1007-1026
Mickiene A, Laiskonis A, Gunther G, Vene S, Lundkvist A, Lindquist L (2002) Tickborne encephalitis in an area of high endemicity in Lithuania: disease severity and long-term prognosis. Clin Infect Dis 35:650-658

Mook-Kanamori BB, Brouwer MC, Geldhoff M, Ende A, van de Beek D (2014) Cerebrospinal fluid complement activation in patients with pneumococcal and meningococcal meningitis. J Inf Secur 68:542-547

Oppermann M, Gotze O (1994) Plasma clearance of the human C5a anaphylatoxin by binding to leucocyte $\mathrm{C} 5 \mathrm{a}$ receptors. Immunology. 82:516-521

Palus M, Formanova P, Salat J, Zampachova E, Elsterova J, Ruzek D (2015) Analysis of serum levels of cytokines, chemokines, growth factors, and monoamine neurotransmitters in patients with tickborne encephalitis: identification of novel inflammatory markers with implications for pathogenesis. J Med Virol 87:885-892

Persson L, Longhi S, Enarsson J, Andersen O, Haghigi S, Nilsson S, Lagging M, Johansson M, Bergström T (2014) Elevated antibody reactivity to measles virus NCORE protein among patients with multiple sclerosis and their healthy siblings with intrathecal oligoclonal immunoglobulin G production. J Clin Virol 61:107-112

Richani K, Soto E, Romero R, Espinoza J, Chaiworapongsa T, Nien JK, Edwin S, Kim YM, Hong JS, Mazor M (2005) Normal pregnancy is characterized by systemic activation of the complement system. J Matern Fetal Neonatal Med 17:239-245

Růžek D, Salát J, Palus M, Gritsun TS, Gould EA, Dyková I, Skallová A, Jelínek J, Kopecký J, Grubhoffer L (2009) CD8+ T-cells mediate immunopathology in tick-borne encephalitis. Virology. 384:1-6

Ruzek D, Salat J, Singh SK, Kopecky J (2011) Breakdown of the bloodbrain barrier during tick-borne encephalitis in mice is not dependent on CD8+ T-cells. PLoS One 6:e20472

Saksida A, Duh D, Lotric-Furlan S, Strle F, Petrovec M, Avsic-Zupanc T (2005) The importance of tick-borne encephalitis virus RNA detection for early differential diagnosis of tick-borne encephalitis. J Clin Virol 33:331-335

Shastri A, Bonifati DM, Kishore U (2013) Innate immunity and neuroinflammation. Mediat Inflamm 2013:342931

Shen L, Zheng J, Wang Y, Zhu M, Zhu H, Cheng Q, Li Q (2017) Increased activity of the complement system in cerebrospinal fluid of the patients with non-HIV Cryptococcal meningitis. BMC Infect Dis 17:7

Stephan AH, Madison DV, Mateos JM, Fraser DA, Lovelett EA, Coutellier L, Kim L, Tsai HH, Huang EJ, Rowitch DH, Berns DS, Tenner AJ, Shamloo M, Barres BA (2013) A dramatic increase of $\mathrm{C} 1 \mathrm{q}$ protein in the CNS during normal aging. J Neurosci 33:1346013474

Stokowska A, Atkins AL, Moran J et al (2017) Complement peptide C3a stimulates neural plasticity after experimental brain ischaemia. Brain. 140:353-369

Tomazic J, Poljak M, Popovic P et al (1997) Tick-borne encephalitis: possibly a fatal disease in its acute stage. PCR amplification of TBE RNA from postmortem brain tissue. Infection 25:41-43

Veje M, Nolskog P, Petzold M, Bergström T, Lindén T, Peker Y, Studahl M (2016) Tick-borne encephalitis sequelae at long-term follow-up: a self-reported case-control study. Acta Neurol Scand 134:434-441

Veje M, Studahl M, Johansson M, Johansson P, Nolskog P, Bergstrom T (2018) Diagnosing tick-borne encephalitis: a re-evaluation of notified cases. Eur J Clin Microbiol Infect Dis 37:339-344 